\title{
Masked Syllable Priming of English Nouns
}

\author{
Niels O. Schiller \\ Cognitive Neuropsychology Laboratory, Department of Psychology, Harvard University
}

This study investigates the role of sublexical units in the phonological encoding of English single-word production in a word-naming task (Experiment 1) and a picture-naming task (Experiment 2). Targets corresponded to bisyllabic English nouns with word-initial stress which varied on the structure of their first syllable: CV (e.g., pi.lot), CVC (e.g., pic.nic), or CV[C] (e.g., pi[1l]ow). ${ }^{1}$ Targets were preceded by a visually masked prime that either matched their first syllable (e.g., pi $\% \%$ - pi.lot) or that was one segment longer (e.g., pil\% $\%$ - pi.lot) or shorter (e.g., pi $\% \% \% \%$ - pic.nic) than the first syllable. Response times were compared to a neutral control condition (e.g., $\% \& \$ \% \%$ - pi.lot) to measure the priming effects (either facilitation or inhibition). Results showed significant facilitation for both the $\mathrm{CV}$ and the CVC conditions. However, contrary to previous findings, there was no interaction between the syllabic structure of the prime and the target. () 1999 Academic Press

Key Words: speech production; phonological encoding; mental lexicon; syllables; masked priming.

Psycholinguistic evidence suggests that the syllable may be a functional unit in the processing of speech, at least in some languages. In speech perception, there is ample evidence that sublexical units, such as the syllable, can be crucial in speech perception and recognition (see Dupoux, 1993, for a recent review). In speech production, the evidence for the functional role of syllables is much weaker (for an overview see Levelt, Roelofs, \& Meyer, 1999). Speech errors that comprise more than one segment cannot unambiguously be attributed to syllables since most of them are confounded with mor-

The work reported in this paper was supported by a grant from NIH NS22201. The author thanks Jennifer Shelton and two anonymous reviewers for many helpful comments on this manuscript.

Address correspondence and reprint requests to Niels O. Schiller, Cognitive Neuropsychology Laboratory, Department of Psychology, Harvard University, 33 Kirkland Street, William James Hall 918, Cambridge, MA 02138. E-mail: nschille@wjh.harvard.edu.

${ }^{1} \mathrm{C}$ stands for consonant, $\mathrm{V}$ for vowel; syllable boundaries are marked by dots, ambisyllabic consonants appear between square brackets. 
phemes, but there are at least some speech errors that are clearly syllabic (for English see MacKay, 1970; for Dutch see Nooteboom, 1969).

Under laboratory conditions, certain aspects of syllable structure and syllabification have been investigated using metalinguistic tasks revealing evidence for the syllable as a psycholinguistic unit at some level in speech production in different languages (for English, see Fallows, 1981 and Treiman, 1983; for Dutch, see Schiller, Meyer, \& Levelt, 1997 and Wheeldon \& Levelt, 1995; for French, see Content, Kearns, \& Frauenfelder, submitted). However, the number-of-syllables effect (Klapp, Anderson, \& Berrian; 1973) on pronunciation latency is confounded with the number of nuclei that have to be encoded phonologically. Recently, it has been shown by Bachoud-Lévi, Dupoux, Cohen, and Mehler (1998) that picture-naming latencies do not depend on the number of syllables of the picture names.

In contradiction to these results, two studies have been reported that found clear syllabic effects in speech production using on-line tasks. Ferrand, Segui, and Grainger (1996) studied the effect of masked syllable primes in naming tasks with French materials. They obtained reliable facilitation effects in picture, word, and nonword naming when prime and target shared the first syllable, relative to a condition where they shared a string of segments of equal length that was either longer or shorter than the first syllable. In a visual lexical decision task-i.e., a task that could be performed without producing the phonological form of the target word - the effect disappeared. Ferrand et al. (1996) concluded that the observed syllable priming effect must arise at the level of the output phonology and that the syllable is a functional unit in French speech production. Recently, Ferrand, Segui, and Humphreys (1997) replicated the syllable priming effect with the word naming task in English.

However, Schiller (1998) was not able to replicate the syllable priming effect in Dutch. In Dutch, phonologically related primes also facilitated the naming of the targets but there was no systematic relationship between the syllabic structure of prime and target. Instead, priming effects were largest when the segmental overlap between prime and target was largest. Therefore, Schiller (1998) called this a segmental overlap effect. Thus, the role of the syllable in speech production remains unclear. This study tries to replicate the syllable priming effect reported by Ferrand et al. (1997) using a word and a picture naming task in English, a language that is quite similar in phonological structure to Dutch.

\section{GENERAL METHOD}

Both experiments used the masked priming paradigm (for details of the procedure see Schiller, 1997, 1998, submitted). First, a row of hash marks (forward mask) was presented on a computer screen for $500 \mathrm{~ms}$, followed by the prime in lower case, presented for $45 \mathrm{~ms}$, followed by another row of hash marks (backward mask), presented for $15 \mathrm{~ms}$. Then the target was presented for maximally $2000 \mathrm{~ms}$. The participants' task was to name the target as fast and 
TABLE 1

Naming Latencies (in ms) and Percentage of Errors (in Parentheses) in Experiment 1

\begin{tabular}{lcccc}
\hline & \multicolumn{4}{c}{ Target type } \\
\cline { 2 - 4 } \multicolumn{1}{c}{ Prime type } & $\begin{array}{c}\text { CV words } \\
(\text { e.g., PILOT) }\end{array}$ & $\begin{array}{c}\text { CVC words } \\
(\text { e.g., PICNIC) }\end{array}$ & $\begin{array}{c}\text { CV[C] words } \\
(\text { e.g., PILLOW) }\end{array}$ & Mean \\
\hline Neutral primes & $469(2.9)$ & $460(0.5)$ & $469(0.0)$ & $466(1.1)$ \\
CV primes & $460(1.4)$ & $452(2.4)$ & $455(1.0)$ & $456(1.6)$ \\
CVC primes & $451(1.4)$ & $441(0.5)$ & $453(1.4)$ & $448(1.1)$ \\
\hline
\end{tabular}

as accurately as possible. Targets disappeared from the screen immediately after response onset and after one second the next trial started. The same 13 participants were tested in Experiments 1 and 2. Seven participants started with Experiment 1, six started with Experiment 2.

\section{EXPERIMENT 1}

In Experiment 1, there were 48 bisyllabic, monomorphemic English nouns, all of which could be assigned unambiguously to one target type $(\mathrm{CV}$, $\mathrm{CVC}$, or $\mathrm{CV}[\mathrm{C}])$. All target words were presented in upper case and preceded by visually masked primes in the three conditions: CV, CVC, and neutral. The resulting 144 trials were randomized individually for each participant.

Results are shown in Table 1. Neither the main effect of target type nor the interaction between target type and prime type was significant. Therefore, the data were pooled across target types for subsequent analyses. The main effect of priming condition was significant ( $p<.001$ for both $F$ values). Target words were named fastest when preceded by a CVC prime, slower when preceded by a CV prime, and slowest when preceded by a neutral prime (all pairwise comparisons $p<.05$ ).

The results did not show any sign of a syllable priming effect. Instead, the obtained facilitation effects may be due to the degree of overlap between prime and target, and the magnitude of the priming effect may be dependent on the amount of overlap, but independent of the correspondence of the syllabic structure of prime and target.

\section{EXPERIMENT 2}

Word naming can be performed by applying nonlexical grapheme-to-phoneme conversion rules. Furthermore, it may be argued that the priming effects obtained in word naming are partially due to the visual overlap between prime and target, although in Experiment 1 an effort was made to avoid this overlap by presenting prime and target in different orthographic case. In contrast, picture naming presumably involves lexical access because the retrieval of a picture's name must be preceded by the activation of the concept 
TABLE 2

Naming Latencies (in ms) and Percentage of Errors (in Parentheses) in Experiment 2

Target type

\begin{tabular}{lcccc}
\cline { 2 - 4 } \multicolumn{1}{c}{ Prime type } & $\begin{array}{c}\text { CV pictures } \\
\text { (e.g., pilot) }\end{array}$ & $\begin{array}{c}\text { CVC pictures } \\
\text { (e.g., picnic) }\end{array}$ & $\begin{array}{c}\text { CV[C] pictures } \\
\text { (e.g., pillow) }\end{array}$ & Mean \\
\hline Neutral primes & $682(3.4)$ & $650(2.9)$ & $653(1.4)$ & $662(2.6)$ \\
CV primes & $628(1.0)$ & $597(2.9)$ & $619(1.9)$ & $614(1.9)$ \\
CVC primes & $622(2.9)$ & $572(1.0)$ & $585(1.9)$ & $592(1.9)$ \\
\hline
\end{tabular}

and the lemma in order to access semantic information (see Glaser, 1992, for a review). Picture naming also avoids the problem of orthographic overlap.

Experiment 2 tested whether the effects found in Experiment 1 can be replicated with picture naming. Materials and task were the same as in Experiment 1 except that the targets were line drawings.

As can be seen in Table 2, the results are similar to those obtained in Experiment 1. The main effect of priming condition was significant $(p<$ .001 for both $F$ values), but not the interaction between target type and priming condition, once again indicating the lack of a syllabic effect. Thus, the data were pooled across target types, and target pictures preceded by a CVC prime were named fastest, followed by the $\mathrm{CV}$ priming condition, and by the neutral priming condition (all pairwise comparisons $p<.05$ ). Thus, the pattern of results is very similar to the outcome of Experiment 1.

\section{CONCLUSION}

Both experiments demonstrated that segmental overlap influences production and, as predicted by the segmental overlap hypothesis (Schiller, 1998), the priming effects increased with an increase in segmental overlap between prime and target. These results are in line with the results obtained in the experiments with Dutch (Schiller, 1998), indicating that the segmental overlap effect may not be language-specific. In fact, the syllable priming effect found in French by Ferrand et al. (1996) may be interpreted as an effect that occurs during the perception and processing of the prime, i.e., an input effect. $^{2}$ Moreover, Carreiras and Grainger (personal communication) failed to obtain the syllable priming effect for Spanish and Costa, Sebastián-Gallés, and Colomé (personal communication) obtained results in Spanish which are inconclusive so far. Furthermore, the effect obtained in this study was consistent across different tasks (word and picture naming). As previously discussed (Schiller, 1998) the syllable priming effect reported by Ferrand et

${ }^{2}$ It may be worth mentioning that Evinck (1997) failed to replicate Ferrand et al. (1996) using the same materials and a similar methodology. 
al. (1997) for English was likely induced by methodological problems and/ or strategic effects. Future research, possibly in non-Indo-European languages, may show whether or not the syllable is a functional unit in phonological encoding.

It may be concluded that at early stages of phonological encoding only segments but not syllables play a functional role in English single word production. In Levelt's model of speech production (Levelt, 1989; Levelt \& Wheeldon, 1994; Levelt et al., 1999) syllabification is a relatively late process during phonological encoding. The results obtained in this study are compatible with this view. Furthermore, this result is consistent with predictions from computational models of speech production (Roelofs, 1997).

\section{REFERENCES}

Bachoud-Lévi, A.-C., Dupoux, E., Cohen, L., \& Mehler, J. 1998. Where is the length effect? A cross-linguistic study of speech production. Journal of Memory and Language, 39, 331-346.

Content, A., Kearns, R., \& Frauenfelder, U. H. (submitted). Boundaries versus onsets in syllabic segmentation.

Dupoux, E. 1993. The time course of prelexical processing: The Syllabic Hypothesis revisited. In: G. T. M. Altmann \& R. Shillcock (Eds.). Cognitive models of speech processing: The Second Sperlonga Meeting (pp. 81-114). Hillsdale, NJ: Erlbaum.

Evinck, S. 1997. Production de la parole en français: Investigation des unités impliquées dans l'encodage phonologique des mots [Speech production in French: Investigation of the units implied during the phonological encoding of words]. Ph.D. dissertation, Bruxelles University.

Fallows, D. 1981. Experimental evidence for English syllabification and syllable structure. Journal of Linguistics, 17, 309-317.

Ferrand, L., Segui, J., \& Grainger, J. 1996. Masked priming of word and picture naming: The role of syllabic units. Journal of Memory and Language, 35, 708-723.

Ferrand, L., Segui, J., \& Humphreys, G. W. 1997. The syllable's role in word naming. Memory and Cognition, 35, 458-470.

Glaser, W. R. 1992. Picture naming. Cognition, 42, 61-105.

Klapp, S. T., Anderson, W. G., \& Berrian, R. W. 1973. Implicit speech in reading reconsidered. Journal of Experimental Psychology, 100, 368-374.

Levelt, W. J. M. 1989. Speaking. From intention to articulation. Cambridge, MA: MIT Press.

Levelt, W. J. M., Roelofs, A., \& Meyer, A. S. (1999). A theory of lexical access in speech production. Behavioral and Brain Sciences, 22, 1-75.

Levelt, W. J. M., \& Wheeldon, L. 1994. Do speakers have access to a mental syllabary? Cognition, 50, 239-269.

MacKay, D. G. 1970. Spoonerisms: The structure of errors in the serial order of speech. Neuropsychologia, 8, 323-350.

Nooteboom, S. 1969. The tongue slips into patterns. In: A. G. Sciarone, A. J. Von Essen, \& A. A. Van Raad (Eds.). Nomen: Leyden studies in linguistics and phonetics (pp. 114132). The Hague: Kluwer.

Roelofs, A. 1997. Syllabification in Speech Production: Evaluation of WEAVER. Language and Cognitive Processes, 12, 657-693. 
Schiller, N. O. 1997. The role of the syllable in speech production. Evidence from lexical statistics, metalinguistics, masked priming, and electromagnetic midsagittal articulography. Ph.D. dissertation, Nijmegen University.

Schiller, N. O. 1998. The effect of visually masked syllable primes on the naming latencies of words and pictures. Journal of Memory and Language, 39, 484-507.

Schiller, N. O. (submitted). Single word production in English: The role of subsyllabic units.

Schiller, N. O., Meyer, A. S., \& Levelt, W. J. M. 1997. The syllabic structure of spoken words: Evidence from the syllabification of intervocalic consonants. Language and Speech, $\mathbf{4 0 ,}$ $103-140$.

Treiman, R. 1983. The structure of spoken syllables: Evidence from novel word games. Cognition, 15, 49-74.

Wheeldon, L., \& Levelt, W. J. M. 1995. Monitoring the time course of phonological encoding. Journal of Memory and Language, 34, 311-334. 